\title{
AIRPLANE CATASTROPHE AS A RESULT OF OPERATIONAL ERRORS AND VIOLATIONS
}

\author{
Alexander Medvedev \\ Transport and Telecommunication Institute, Lomonosova 1, Riga, LV-1019, Latvia \\ E-mail: medvedevs.a@tsi.lv
}

Received 22 February 2012; accepted 20 May 2013

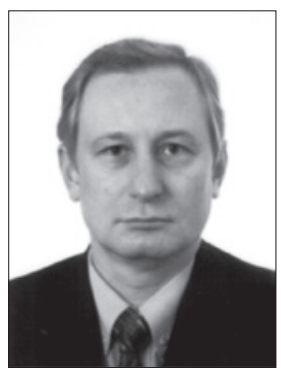

\begin{abstract}
Alexander MEDVEDEV, Dr Sc. Eng.
Education: studied mechanical science at the Riga Civil Aviation Engineering

Institute and obtained an engineer's diploma in 1985. Dr Sc. Eng. (1995),

Riga Aviation University.

Affiliation and functions: professor; head of the Chair of Aviation Transport; member of the TTI Research Committee; member of the Latvian Operation Research Society; member of the Latvian Association of Professors at Institutions of Higher Education; manager of theoretical training and examination at TTI, an academic and professional aviation centre.

Research interests: transport and logistics.

Publications: 3 inventions, 80 scientific papers and instructional books.
\end{abstract}

\begin{abstract}
In 2006 an accident occurred when a Cessna 152 training aircraft was carrying out a training flight. After taking off, the aircraft engine started to work sporadically as the aircraft gained altitude, and then it stopped. The aircraft crashed. During the crash, the aircraft was damaged and set on fire. Two people, the pilot-instructor and the trainee-pilot perished in the catastrophe. Aircraft of this type are not equipped with flight data recorders. As a result, it is a problem to objectively get information about the cause of the aircraft accident. With consideration of the available information (the investigation report and aircraft operating manual), the current paper contains the following: the pilot-instructor's possible operational analysis when preparing for the flight, the schemes of possible flight directions and trajectories in the situation, the scenarios of the operations the pilot could have made and the possible motion of the aircraft, the estimates that were conducted, and judgement of the pilot-instructor's operations during the accident according to the requirements of operational standards.
\end{abstract}

Keywords: aircraft operating manual, rules violation, human factor, aircraft accident, action analysis.

\section{Introduction}

According to the concept based on psychology, the source of error resides in a human and is the result of concrete psychosocial mechanisms that are studied and explained by different types of scientific research and applied psychology.

During the examination of flight safety, operational errors are traditionally considered a contributory factor in most aviation occurrences. According to statistical estimates, every day millions of errors are made before a serious failure in flight safety occurs. Without consideration of yearly minor oscillations, statistics in this sector over the past 10 years proceed from the assumption that the frequency of aviation incidents is less than one catastrophe for one million departures.

In flight safety management, it is extremely important to understand and clearly distinguish between errors and violations. The main difference between operational mistakes and violations is intention. While a mistake is a not intentional action, a violation is a wilful action. People who make operational mistakes try to take the necessary counteractions. On the contrary, people whom commit violations know that their actions lead to deviations from the rules, regulations, standards and practices, but they nevertheless persist in their intent (Safety Management ... 2009).

\section{Description of the situation}

A planned educational and training flight with a rectangular route in accordance with the curriculum took place in area $I$ on the day of the catastrophe. The training flight was held in an uncontrolled airspace in accordance with the requirements of visual flight rules. 
Take-off and landing were done on a primer runway with turf. The take-off procedure assumes 'altitude climb up to $300 \mathrm{ft}$. $(\approx 100 \mathrm{~m})$ over the level of obstructions before the first 90-degree turn for the execution of a rectangular route.

According to witnesses, the engine started to work irregularly after take-off, while climbing and before the start of the first turn. The aircraft started the manoeuvre with an engine malfunction. While the pilot was making the 90-degree turn, the engine stopped. The aircraft abruptly lost altitude and with a roll of 30-40 degrees to the right hit the ground. The two pilots were killed. The relative position of the runway and the aircraft crash site is shown in figure 1 .

Due to the lack of an on-board flight data recorder, a conclusion about the engine stopping can only be made from materials compiled during the official investigation, which allow one to assume that the technical state of the engine was not the cause for it stopping.

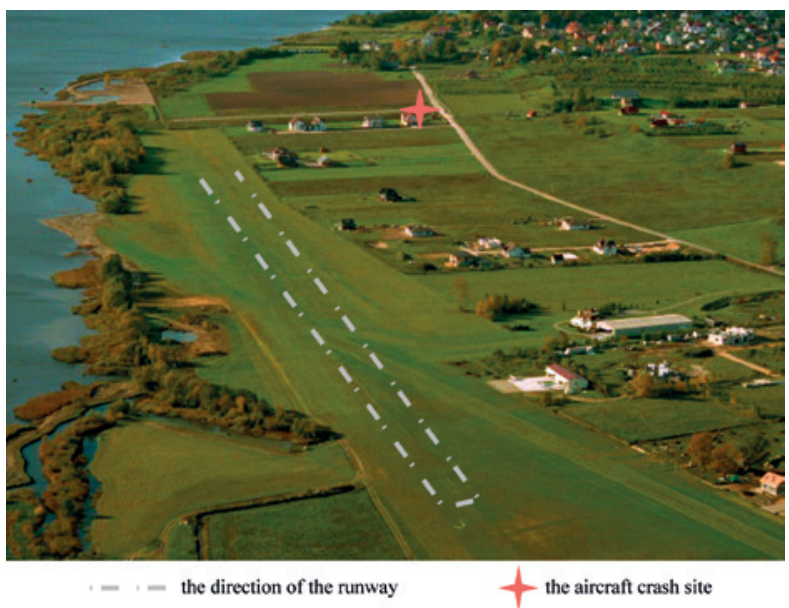

Fig. 1. The relative position of the runway and the aircraft crash site

At this stage of the flight (take-off and climb), the aircraft is accelerating (increasing in speed). One possible reason for the malfunction and later stop of the engine could be insufficient fuel in the aircraft tanks. Specifically, in this aircraft, fuel from the tanks situated in these wings is supplied to the engine by gravity flow (Pilot's Operating ... 2003). One common reason for interruptions in the functioning of a piston engine, with possible forthcoming full stop, is significant depletion of the air-fuel mixture. If there is only a small amount of fuel in the tanks on take-off and altitude gain up to $100 \mathrm{~m}$, the fuel, under influence of inertia and gravity, moves to the back side of the tank, which could provoke insufficient supply of fuel to the engine carburettor.

If a pilot stops climbing (changes to horizontal flight), the fuel could start flowing into the carburettor and the engine will begin working in a short time. But because of insufficient engine thrust, a pilot has either to increase the aircraft angle of attack or to descend with an angle of glide of approximately 6 degrees. In both cases, the fuel could again stop going into the engine (or go to the back or front side of the tank).

Next comes the analysis of the pilot's possible actions, and on this basis we will make conclusions about the possibilities to avoid a catastrophe.

\section{Conditions for the analysis of the actions of the pilot of the Cessna 152}

1. In accordance with the instruction manual, for the summertime operation of the Cessna 152, minimal speed during manoeuvring (minimal handling speed) is not less than 93 KIAS (Pilot's Operating ... 2003), which approximately equals $172 \mathrm{~km} / \mathrm{h}(\approx 47.7 \mathrm{~m} / \mathrm{s})$.

2. Since on some part of the trajectory the aircraft was flying with a malfunctioning engine, its speed could have been significantly lower and it could have reached a gliding speed of 60 KIAS (Pilot's Operating ... 2003) or $110 \mathrm{~km} / \mathrm{h}$ $(\approx 30.5 \mathrm{~m} / \mathrm{s})$, flaps up.

3. Because of the lack of data about the aircraft's actual speed of flight, two scenarios were taken into consideration:

4. the first was engine stop at flight speed of $47.7 \mathrm{~m} / \mathrm{s}$,

5. the second was the engine stop at flight speed of $30.5 \mathrm{~m} / \mathrm{s}$.

6. The maximum flight altitude with a failed engine is $300 \mathrm{ft}$. or $\approx 100 \mathrm{~m}$.

7. Altitude loss because of speed reduction due to insufficient or no engine thrust as a result of engine malfunction or complete stop was not taken into consideration.

8. Altitude loss due to glide was not used in altitude calculations.

\section{Calculation of evaluations}

If a pilot makes a manoeuvre, in this case a correct turn keeping constant flight altitude (it is necessary to keep lifting force equal to aircraft weight), it is necessary to increase:

- either flight speed,

- or angle of attack.

If a pilot does not increase flight speed or angle of attack, the aircraft during a correct turn ${ }^{1}$ starts to lose altitude (descends). If an engine is malfunctioning or working with interruptions, then it is impossible to increase speed. The increase in angle of attack is also limited by the conditions of summertime operation; it is prohibited to exceed critical angles of attack.

\footnotetext{
${ }^{1}$ Correct turn: turn with constant speed, constant roll, and without drift (turn angle less than 360 degrees). (Kastorskii 1970: 154)
} 


\subsection{Option No. 1}

Flight design speed: minimal speed with which manoeuvring is allowed should not be less than $172 \mathrm{~km} / \mathrm{h}$ or $\approx 47.7 \mathrm{~m} / \mathrm{s}$. In accordance with the requirements for flying standards for passenger aircraft, for passenger comfort the angle of roll should not exceed 30 degrees (Nikolaev 1990). This roll angle matches maximum normal load factor $n_{\mathrm{y}(\max )}=1.15$.

To make an assumption that the turn was performed with load factor 1.15, for securing enough lift force, the air speed should then increase.

$$
\begin{aligned}
& V_{\min }=\sqrt{\frac{2 \cdot G \cdot n_{y(\max )}}{C_{y} \cdot \rho \cdot S}}=V_{h} \cdot \sqrt{n_{y(\max )}}= \\
& 172 \cdot \sqrt{1.15}=172 \cdot 1.07=184(\mathrm{~km} / \mathrm{h}),
\end{aligned}
$$

or $\approx 51 \mathrm{~m} / \mathrm{s}$,

where $G$ is an aircraft weight, $C_{y}$ - lift coefficient of the wing in this configuration, $S$ - wing area, $\rho$ - air density, $V_{h}$ - horizontal flight speed.

If the engine is functioning with interruptions or has stopped and if the angle of attack is constant when performing a turn, vertical descent speed should increase (Kastorskii 1970).

$$
\begin{aligned}
& \Delta V=\sqrt{V_{\min }^{2}-V_{h}^{2}}= \\
& \sqrt{184^{2}-172^{2}} \approx 65.4(\mathrm{~km} / \mathrm{h}),
\end{aligned}
$$

or $\approx 18.2(\mathrm{~m} / \mathrm{s})$.

In further calculations, the turning speed descent is assumed to be $\Delta V=18 \mathrm{~m} / \mathrm{s}$.

For this overload value, it is possible to calculate the value of the minimal turn radius (Kastorskii 1970).

$$
\begin{aligned}
& r_{\min }=\frac{V_{h}^{2}}{g \cdot \sqrt{n_{y(\max )}^{2}-1}}=\frac{1}{9.81 \cdot \sqrt{1.15^{2}-1}} \cdot V_{h}^{2} \approx \\
& 0.18 \cdot V_{h}^{2} \approx 409(\mathrm{~m}) .
\end{aligned}
$$

In further calculations, we assume that $r_{\min }=$ $400 \mathrm{~m}$. Accordingly it is possible to calculate the time necessary to perform a 90-degree turn:

$$
\begin{aligned}
& t=\frac{L_{90}}{V_{\min }}=\frac{\pi \cdot r_{\min }}{2 \cdot V_{\min }}= \\
& \frac{3.14 \cdot 400}{2 \cdot 47.7} \approx 13.2(\mathrm{~s}) .
\end{aligned}
$$

Let us assume that the turn had taken only $t=12 \mathrm{~s}$ (the engine was possibly working even with interruptions). But this situation is unlikely. Moving at such a trajectory (preserving the same altitude and speed of flight), the aircraft would have been far away from the place it crashed (lines No. 11 and 12, or position No. 7 in line No. 5, Fig. 2).

If the turn had started at an altitude of $100 \mathrm{~m}$, then accordingly the aircraft would have lost altitude while performing the turn by:

$$
\Delta H=\Delta V \cdot t=18 \cdot 12=216(\mathrm{~m}) .
$$

In that case, altitude of $100 \mathrm{~m}$ simply would not have been enough for a pilot to perform a turn of $90 \mathrm{de}-$ grees!

To proceed with an assumed starting altitude of $100 \mathrm{~m}$ for calculation and also the relative positions of the runway and aircraft crash site, the aircraft (moving by trajectory No. 6, Fig. 2) could perform a turn of only about 45 degrees. Let us assume that the time from the start of the turn until the moment of the crash equals $6 \mathrm{~s}$ (half of the time necessary for a 90-degree turn). At that moment, the aircraft had to lose altitude for not less than:

$$
\Delta H=\Delta V \cdot \frac{t}{2}=18 \cdot \frac{12}{2}=108(\mathrm{~m}) .
$$

But in that case on the estimated line of flight there is an obstacle, a house (Fig. 2, line No. 6).

That the aircraft moved by trajectory No. 5 (Fig. 2) is unlikely and will not be further considered.

Therefore, the aircraft practically could not get to the crash site. It should have hit the ground or a possible obstacle (a house for example).

On that basis, we can assume that the aircraft was flying with a speed less than allowed for making a manoeuvre, which should be considered at least the instructor-pilot's mistake.

\subsection{Option No. 2}

Estimated flight speed: maximum gliding speed of $110 \mathrm{~km} / \mathrm{h}$ or $\approx 30.5 \mathrm{~m} / \mathrm{s}$, flaps up.

Based on figure 3 (Pilot's Operating ... 2003) it is possible to determine the maximum aircraft gliding range with a stopped engine from a height of $100 \mathrm{~m}$ (if the pilot executed all the necessary procedures):

- flight speed - 60 KIAS $(110 \mathrm{~km} / \mathrm{h})$;

- propeller windmilling;

- flaps up;

- zero wind.

Accordingly for the estimated flight altitude of $\approx 100 \mathrm{~m}$ and specified earlier conditions, the maximum gliding distance could be:

$$
L_{H=100}=\frac{22000 \cdot 100}{2440} \approx 900(\mathrm{~m}) .
$$

In other words, with every 100 metres of horizontal movement, the aircraft loses $\approx 11 \mathrm{~m}$ of altitude.

As was mentioned earlier, in accordance with summertime flight rules for passenger aircraft, the angle of roll in turns should not exceed 30 degrees. This roll angle matches maximum normal load factor $n_{y(\max )}$ $=1.15$.

At a height of $8,000 \mathrm{ft}$. $(\approx 2,440 \mathrm{~m})$, maximum gliding distance could reach 12 nautical miles $(\approx 22,000 \mathrm{~m})^{2}$.

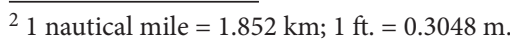




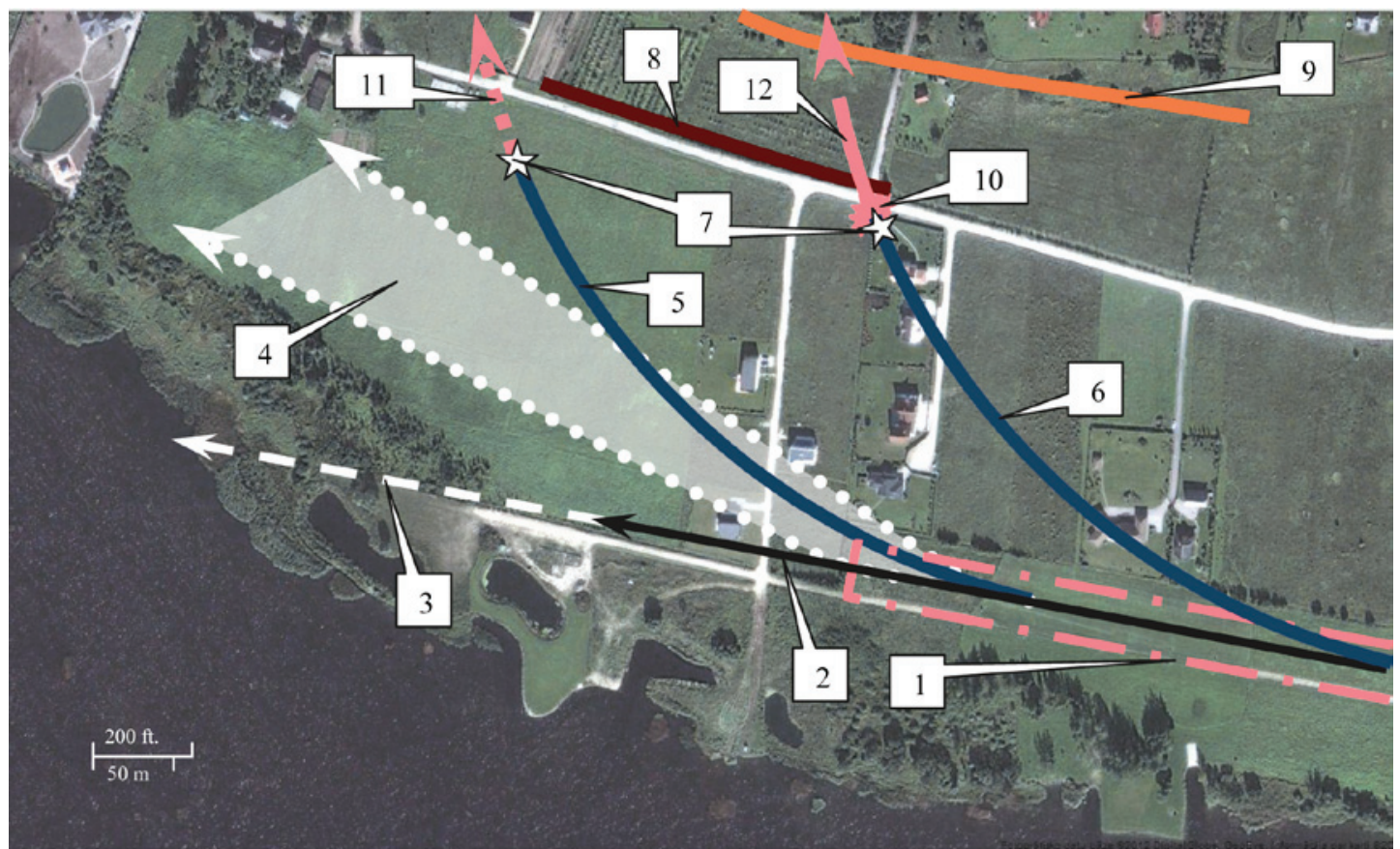

Fig. 2. Satellite photo of the Cessna 152 crash site with an explanation scheme for calculation option No 1:

1) take-off runway; 2) take-off heading; 3) direction of aircraft if the engine had shut down in flight and no additional manoeuvering had taken place (as per FM: flight manual); 4) allowable range of manoeuvering if the engine had shut down in flight (as per FM); $5)-6$ ) the possible range of trajectories for the plane; 7) the turning point for the aicraft at 45 degrees against the take-off line; 8) electrical power lines and fence; 9) place where terrain starts to rise; 10) the location of the crash; 11) - 12) it is not possible to continue the movement of aircraft in order to make a turn of 90 degrees because of barriers)

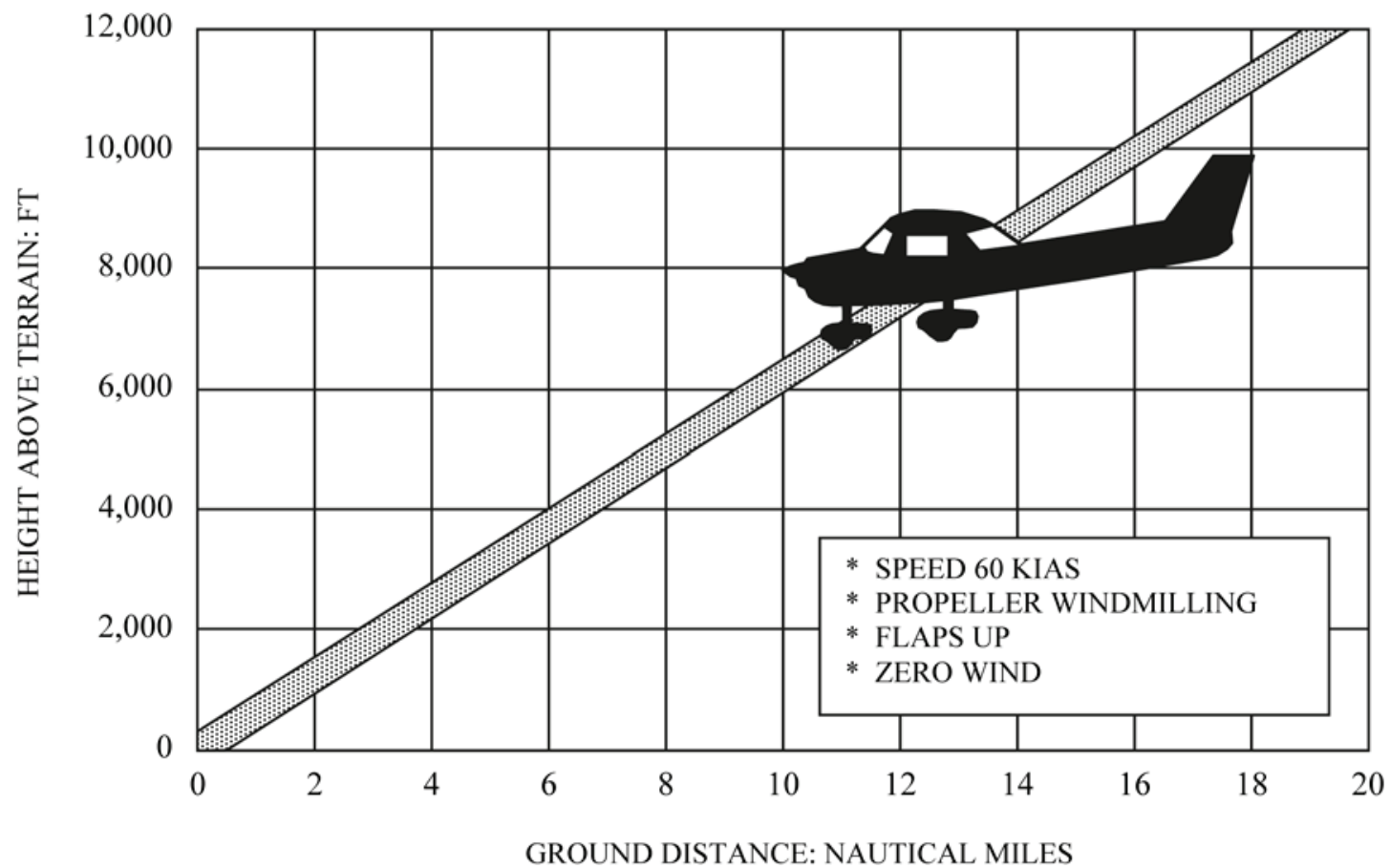

Fig. 3. Maximum glide 
If the engine was working with interruptions at the time the aircraft was flying in a straight line (the takeoff line), the pilot should have followed these guidelines: 'Prompt lowering of the nose to maintain airspeed and establishing a glide attitude is the first response to an engine failure after take-off. In most cases, the landing should be planned straight ahead with only small changes in direction to avoid obstructions' (Pilot's Operating ... 2003). In other words, the flight path should have followed lines No 3 or 4 .

\section{Possible aircraft trajectories and pilot actions}

If we assume that the turn was performed with overload of 1.15 , then to secure necessary lift force, air speed should have been increased to:

$$
\begin{aligned}
& V_{\min }=\sqrt{\frac{2 \cdot G \cdot n_{y(\max )}}{C_{y} \cdot \rho \cdot S}}=V_{h} \cdot \sqrt{n_{y(\max )}}= \\
& 110 \cdot \sqrt{1.15}=117(\mathrm{~km} / \mathrm{h}),
\end{aligned}
$$

or $\approx 32.5 \mathrm{~m} / \mathrm{s}$.

If the engine is working with interruptions or not working at all and there is a constant angle of attack, vertical descent speed will further increase to the following while a turn is being performed:

$$
\begin{aligned}
& \Delta V=\sqrt{V_{\min }^{2}-V_{h}^{2}}= \\
& \sqrt{117^{2}-110^{2}} \approx 39(\mathrm{~km} / \mathrm{h}),
\end{aligned}
$$

In further calculations, additional descent speed during the turn will be assumed to be $10 \mathrm{~m} / \mathrm{s}$.

With maximum acceptable values of overload $\left(n_{y(\max )}=1.15\right)$ and roll angle $(\gamma=30$ degrees $)$, minimal turn radius will be:

$$
r_{\min }=\frac{V_{h}^{2}}{g \cdot \sqrt{n_{y(\max )}^{2}-1}}=\frac{1}{9.81 \cdot \sqrt{1.15^{2}-1}} \cdot V_{h l}^{2} \approx
$$

$0.18 \cdot V_{\min }^{2}=0.18 \cdot 30.5^{2} \approx 167(\mathrm{~m})$.

In further calculations, let us assume that $r_{\min }=165 \mathrm{~m}$.

Accordingly, the time necessary to perform a 90-degree turn will be:

$$
t=\frac{L_{90}}{V_{\min }}=\frac{\pi \cdot r_{\min }}{2 \cdot V_{\min }}=\frac{3.14 \cdot 165}{2 \cdot 30.5} \approx 8.5(\mathrm{~s}) .
$$

Let us assume that the turn took $8 \mathrm{~s}$.

If the turn was started at an altitude of $100 \mathrm{~m}$, then accordingly, while the turn was being performed, the aircraft could lose altitude of not less than:

$$
\Delta H=\Delta V \cdot t=10 \cdot 8=80(\mathrm{~m}) .
$$

In that case (after finishing a 90-degree turn), directly in the path of the aircraft there are some obstacles: a fence, a power line 15-m high, and after that a rise in the terrain. Due to that, the pilot could have acted in the following ways (Fig. 4):

or $\approx 10.8(\mathrm{~m} / \mathrm{s})$.

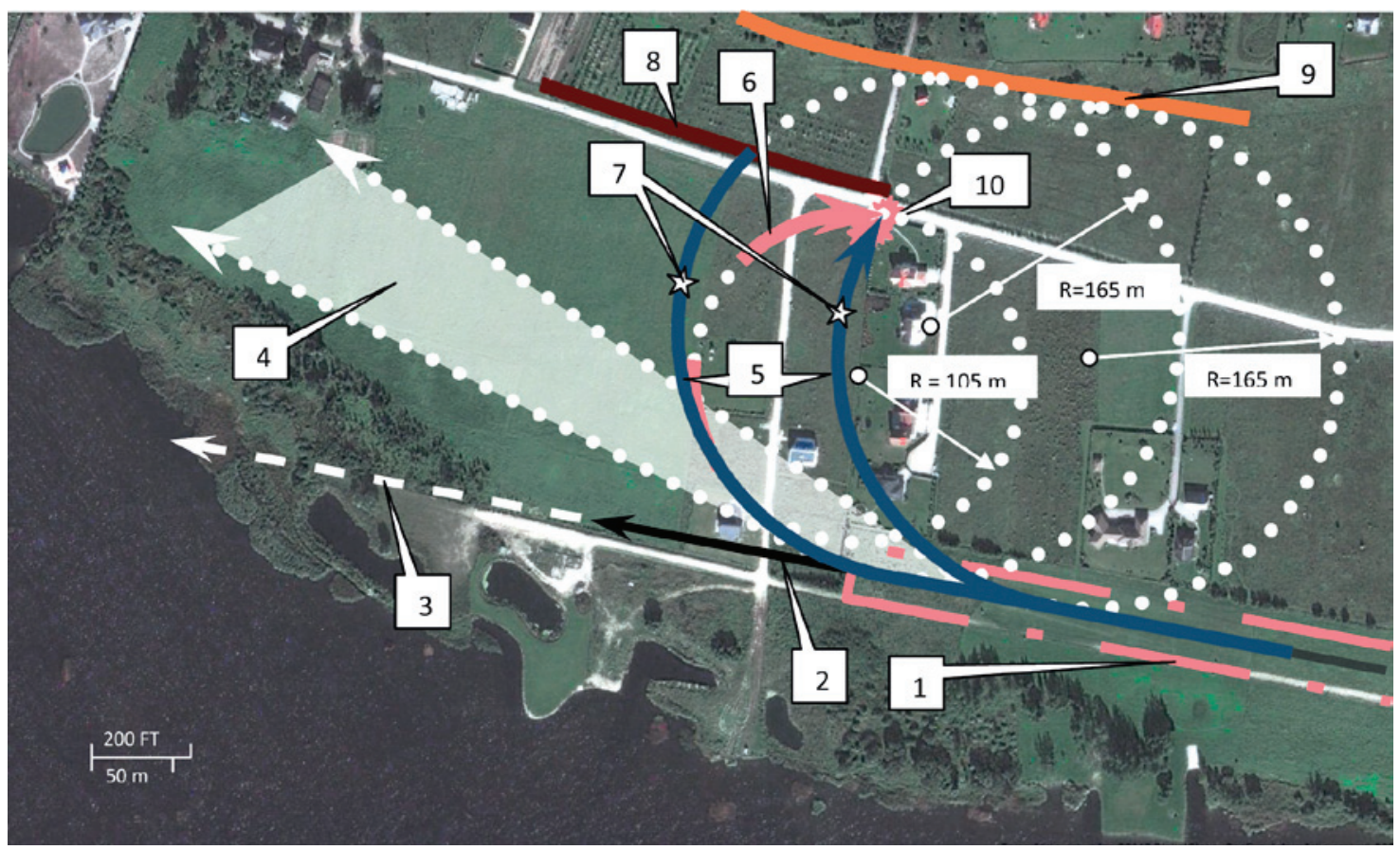

Fig. 4. Satellite photo of the Cessna 152 crash site, with an explanation scheme for calculation option No 2: 1) take-off runway; 2) take-off heading; 3) direction of aircraft if engine had shut down in flight and no additional manoeuvering had taken place (as per FM); 4) allowable range of maneuvering if engine had shut down in flight (as per FM) and attempts were made to avoid obstacles; 5) the possible range of trajectories for the plane; 6) one of the most abrupt aircraft flight paths; 7) point at which aircraft has made a turn of 90 degrees from original heading; 8) electrical power lines and fence; 9) onset of a rise in the terrain; 10) the location of the crash 
1. Following path No 5. The pilot quite possibly was trying to maintain altitude while continuing to perform the turn (so that it would be possible to pass over the power line), increasing the angle of attack.

2. Following path No 6. Even if the pilot started to perform the turn with a bigger radius $(165 \mathrm{~m})$ and understood that he would not be able to overcome the obstacles (fence, power line, and rise in terrain), when starting to decrease the radius of the turn, he would still even more increase vertical altitude loss.

For a turn radius of $105 \mathrm{~m}$ (short-dashed line in figure 4), the overload will be:

$$
\begin{aligned}
& n_{y}=\sqrt{\left(\frac{V_{h}^{2}}{r_{\min } \cdot g}\right)^{2}+1}= \\
& \sqrt{\left(\frac{30.5^{2}}{105 \cdot 9.81}\right)^{2}+1}=1.346 \text {. }
\end{aligned}
$$

Necessary air speed:

$$
\begin{aligned}
& V_{\min }=V_{h} \cdot \sqrt{n_{y}}= \\
& 110 \cdot \sqrt{1.346} \approx 128(\mathrm{~km} / \mathrm{h}),
\end{aligned}
$$

or $\approx 35(\mathrm{~m} / \mathrm{s})$.

Additional vertical descent speed could be:

$$
\begin{aligned}
& \Delta V=\sqrt{V_{\min }^{2}-V_{h}^{2}}= \\
& \sqrt{128^{2}-110^{2}} \approx 65(\mathrm{~km} / \mathrm{h}),
\end{aligned}
$$

or $\approx 18(\mathrm{~m} / \mathrm{s})$.

Let us assume that the pilot also performed a 90 -degree turn with a radius of $105 \mathrm{~m}$.

Turning time will be:

$$
\begin{aligned}
& t=\frac{L_{90}}{V_{h}}=\frac{\pi \cdot r_{\min }}{2 \cdot V_{h}}= \\
& \frac{3.14 \cdot 105}{2 \cdot 30.5} \approx 5.4(\mathrm{~s}) .
\end{aligned}
$$

If we assume that turning time is $5 \mathrm{~s}$, then during that time the aircraft could additionally lose altitude of:

$$
\Delta H=\Delta V \cdot t=18 \cdot 5=90(\mathrm{~m}) .
$$

These calculations do not count altitude loses due to gliding! In that case, the pilot should have lifted the aircraft nose, increasing the angle of attack (to slow the descent of the aircraft).

3. Possible intermediate options between paths No 5 and No 6.

In any case (No 1, 2 or 3), to keep the altitude at the same level the pilot had to increase the angle of attack, which caused the angle of attack to become critical for the aircraft and led to flow separation from a wing and rapid decrease in lift force. Since the pilot was performing a right turn, the aircraft should have fallen on its inner (right) wing. The investigation materials and the position of the aircraft on the ground confirm this.

\section{Conclusions}

1. The pilot's actions, performing a right turn relative to take-off path in this situation (with the engine stopped), could be considered a violation against the requirement of the pilot's operating handbook and FAA-approved airplane flight manual.

2. The pilot's actions during the initial emergency at an altitude of approximately $100 \mathrm{~m}$ :

- With presence of the obstacles in the direction that the pilot turned the aircraft (to the right of the take-off path), this could not lead to a safe completion of the flight;

- As a result of the violation of guidebook recommendations for operating the aircraft during summertime and for performing a forced landing, an emergency turned into a catastrophe.

3. If the pilot had followed the recommendations from the guidebook for operating the aircraft during summertime, he could have performed an emergency landing on water (dashed line No 3, Figs 2 and 4) or in a field (sector 4, Figs 2 and 4). The guidebook states that in case of engine malfunction the following should be done: "Prompt lowering of the nose to maintain airspeed and establish a glide attitude is the first response to an engine failure after take-off. In most cases, the landing should be planned straight ahead with only small changes in direction to avoid obstructions". The aircraft would have been damaged, but the people (crew) could have survived.

\section{References}

Kastorskii, V. E. (Ed.). 1970. Aerodinamika i Dinamika Poliota Transportnyh Letatelnyh Apparatov. 2. Dinamika poliota. Riga: RKIIGA, 624 s. (in Russian).

Nikolaev, L. F. 1990, Aerodinamika i Dinamika Poliota Transportnyh Samoliotov. Moskva: Transport. 392 s. (in Russian). Pilot's Operating Handbook and FAA Approved Airplane Flight Manual. 2003. N49696.

Safety Management Manual (SMM). 2009. Doc 9859 AN/474 ICAO. 2nd ed. 